Lenka Novakova, MD

Henrik Zetterberg, MD,

$\mathrm{PhD}$

Peter Sundström, MD,

$\mathrm{PhD}$

Markus Axelsson, MD,

$\mathrm{PhD}$

Mohsen Khademi, PhD

Martin Gunnarsson, MD,

$\mathrm{PhD}$

Clas Malmeström, MD,

$\mathrm{PhD}$

Anders Svenningsson, $\mathrm{MD}, \mathrm{PhD}$

Tomas Olsson, MD, PhD Fredrik Piehl, MD, PhD

Kaj Blennow, MD, PhD

Jan Lycke, MD, PhD

Correspondence to

Dr. Novakova:

lenka.novakova@vgregion.se

Supplemental data at Neurology.org

\section{Monitoring disease activity in multiple sclerosis using serum neurofilament light protein OPEN}

\section{ABSTRACT}

Objective: To examine the effects of disease activity, disability, and disease-modifying therapies (DMTs) on serum neurofilament light (NFL) and the correlation between NFL concentrations in serum and CSF in multiple sclerosis (MS).

Methods: NFL concentrations were measured in paired serum and CSF samples ( $n=521)$ from 373 participants: 286 had MS, 45 had other neurologic conditions, and 42 were healthy controls (HCs). In 138 patients with MS, the serum and CSF samples were obtained before and after DMT treatment with a median interval of 12 months. The CSF NFL concentration was measured with the UmanDiagnostics NF-light enzyme-linked immunosorbent assay. The serum NFL concentration was measured with an in-house ultrasensitive single-molecule array assay.

Results: In MS, the correlation between serum and CSF NFL was $r=0.62(p<0.001)$. Serum concentrations were significantly higher in patients with relapsing-remitting MS (16.9 ng/L) and in patients with progressive MS (23 ng/L) than in HCs $(10.5 \mathrm{ng} / \mathrm{L}, \mathrm{p}<0.001$ and $p<0.001$, respectively). Treatment with DMT reduced median serum NFL levels from 18.6 (interquartile range [IQR] 12.6-32.7) ng/L to 15.7 (IQR 9.6-22.7) ng/L ( $p<0.001$ ). Patients with relapse or with radiologic activity had significantly higher serum NFL levels than those in remission $(p<0.001)$ or those without new lesions on MRI $(p<0.001)$.

Conclusions: Serum and CSF NFL levels were highly correlated, indicating that blood sampling can replace CSF taps for this particular marker. Disease activity and DMT had similar effects on serum and CSF NFL concentrations. Repeated NFL determinations in peripheral blood for detecting axonal damage may represent new possibilities in MS monitoring. Neurology ${ }^{\circledR}$ 2017;89:2230-2237

\section{GLOSSARY}

AUC = area under the curve; $\mathbf{C I}=$ confidence interval; DMT = disease-modifying therapy; EDSS = Expanded Disability Status Scale; ELISA = enzyme-linked immunosorbent assay; $\mathbf{H C}=$ healthy control; INDC = control with inflammatory neurologic disease; LLoQ = lower limit of quantification; $\mathbf{M S}=$ multiple sclerosis; NEDA = no evidence of disease activity; NFL = neurofilament light; OND = other neurologic disorder or symptom; ROC = receiver operating characteristic; RRMS = relapsing-remitting multiple sclerosis; Simoa $=$ single-molecule array.

Neurofilament light (NFL) protein is one of the most studied biomarkers of disease activity and treatment response in patients with multiple sclerosis (MS). Neurofilaments are structural components of myelinated axons that are composed of subunits known as light, medium, heavy, $\alpha$-internexin, and peripherin. Neurofilaments are released into the CSF after axonal injury ${ }^{1}$ during various neurologic disorders, including MS. ${ }^{2}$

In MS, the concentration of CSF NFL is increased during relapse and in conjunction with contrast-enhancing lesions on MRI. ${ }^{3-6}$ The concentration is decreased by effective treatment with disease-modifying therapies (DMTs). ${ }^{3,4,7}$ The CSF NFL concentration at disease onset may

\footnotetext{
From the Department of Clinical Neuroscience (L.N., M.A., C.M., J.L.) and Department of Psychiatry and Neurochemistry (H.Z., K.B.), Institute of Neuroscience and Physiology at Sahlgrenska Academy, University of Gothenburg; Clinical Neurochemistry Laboratory (H.Z., K.B.), Sahlgrenska University Hospital, Mölndal, Sweden; Department of Molecular Neuroscience (H.Z.), UCL Institute of Neurology, London, UK; Department of Pharmacology and Clinical Neuroscience (P.S.), Umeå University; University Department of Clinical Neuroscience (M.K., T.O., F.P.), Neuroimmunology Unit, and Department of Clinical Sciences (A.S.), Danderyd Hospital, Karolinska Institutet, Stockholm; and Department of Neurology (M.G.), Faculty of Medicine and Health, Örebro University, Sweden.

Go to Neurology.org for full disclosures. Funding information and disclosures deemed relevant by the authors, if any, are provided at the end of the article. The Article Processing Charge was funded by Swedish Research Council.

This is an open access article distributed under the terms of the Creative Commons Attribution License 4.0 (CC BY), which permits unrestricted use, distribution, and reproduction in any medium, provided the original work is properly cited.
} 
predict disease severity. ${ }^{8,9}$ The sensitivity of the immunoassay has been improved, making it possible to determine NFL levels as low as those found in the CSF of healthy controls (HCs). ${ }^{1}$

Recent technical developments have given rise to ultrasensitive antibody-based analytic techniques such as the single-molecule array (Simoa) technology, which enables quantification of protein biomarkers in blood samples at very low concentrations. ${ }^{10}$ We recently developed a Simoa method for NFL in blood samples (serum or plasma) that has markedly improved analytic sensitivity compared to standard enzyme-linked immunosorbent assay (ELISA) or electrochemiluminescence immunoassays, allowing accurate measurement of NFL in blood down to concentrations occurring in healthy persons. ${ }^{11}$ Using the Simoa assay, blood NFL has shown promise as a biomarker for HIV encephalopathy, ${ }^{12}$ severe traumatic brain injury, ${ }^{13}$ sports-related mild traumatic brain injury, ${ }^{14}$ postconcussion syndrome, ${ }^{15}$ and MS. ${ }^{16}$

Currently, we are still lacking a reliable blood biomarker for evaluating CNS injury in MS. In this study, NFL concentrations were measured in 521 paired serum and CSF samples collected at 4 university hospitals in
Sweden. The aims were to investigate the correlation between serum and CSF NFL concentrations and to investigate the effects of disease activity, disability, and DMTs on serum NFL concentrations in MS.

METHODS Patients and HCs. Patients with MS $(\mathrm{n}=286)$ fulfilling the revised McDonald criteria, ${ }^{17}$ patients with other neurologic disorders or symptoms (ONDs, $\mathrm{n}=45)$, and HCs $(\mathrm{n}=42)^{18}$ were consecutively enrolled in the study at the neurology departments of 4 Swedish hospitals: Umeå University Hospital, Umeå; Sahlgrenska University Hospital, Gothenburg; Karolinska University Hospital, Stockholm; and Örebro University Hospital, Örebro (table).

The 286 patients with MS consisted of 204 with relapsingremitting MS (RRMS) and 82 with progressive MS; the latter group included 19 with primary progressive MS and 63 with secondary progressive MS. A subgroup of these patients $(n=148)$, including 98 with RRMS and 50 with progressive MS, were followed up prospectively and examined before and again after a median of 12 months (range $0-46$ months). A small proportion remained untreated $(\mathrm{n}=10)$, and the remaining $(\mathrm{n}=138)$ were treated with the following DMTs: glatiramer acetate $(n=2)$, glatiramer acetate plus mitoxantrone $(n=1)$, interferon- $\beta$ ( $n=$ $3)$, oral weekly methotrexate $(n=7)$, mitoxantrone $(n=15)$, fingolimod $(n=21)$, rituximab $(n=23)$, natalizumab $(n=63)$, alemtuzumab $(n=2)$, and cyclophosphamide $(n=1)$. In conjunction with baseline sampling, most patients escalated their DMT $(n=68)$ from less effective DMTs (interferon- $\beta$, glatiramer acetate, high doses of IV immunoglobulin, or oral weekly methotrexate) to more effective DMTs (alemtuzumab, cyclophosphamide, fingolimod, glatiramer acetate plus mitoxantrone, mitoxantrone, natalizumab, or rituximab). ${ }^{19} \mathrm{~A}$ second group of patients were not being treated at the time of sampling and either were treatment naive $(\mathrm{n}=36)$ or had a prior treatment

\begin{tabular}{|c|c|c|c|c|c|c|c|}
\hline Demograp & hic data and & NFL conc & entrations of patier & ts and controls & & & \\
\hline SCs $(n=14)$ & $40(22-65)$ & $4 / 10$ & $6.8(3.5-17.9)$ & $295(140-650)$ & NA & NA & NA \\
\hline NINDCs $(n=16)$ & $34(20-71)$ & $8 / 8$ & 7.2 (3.7-20.8) & 270 (85-790) & NA & NA & NA \\
\hline \multicolumn{8}{|l|}{ RRMS } \\
\hline All $(n=204)$ & 37 (14-64) & $61 / 143$ & $16.9(1.6-1,480)$ & $730(130-111,920)$ & $2.6 / 2.5(0-8.5)$ & $4.29 / 4.13(0.16-9.98)$ & 58 \\
\hline \multicolumn{8}{|l|}{ Follow-up (n = 98) } \\
\hline Before treatment & 35 (14-60) & $34 / 64$ & $16.9(1.9-420)$ & $680(133-27,310)$ & $2.7 / 2.5(0-6.5)$ & $4.28 / 3.90(0.16-9.08)$ & 58 \\
\hline \multicolumn{8}{|l|}{ Follow-up $(n=50)$} \\
\hline Before treatment & $48(22-67)$ & $25 / 25$ & $23.6(10.8-313)$ & $844(302-12,900)$ & $5.6 / 6.0(2.5-8.5)$ & 7.00/7.18 (1.26-9.97) & 45 \\
\hline After treatment & $49(24-68)$ & $25 / 25$ & $22.7(10-180)$ & $630(280-24,420)$ & $5.6 / 6.0(3.0-8.5)$ & $6.45 / 6.58(1.45-9.89)$ & 16 \\
\hline
\end{tabular}

Abbreviations: $\mathrm{HC}=$ healthy control; INDC = control with inflammatory disease; MS = multiple sclerosis; MSSS = Multiple Sclerosis Severity Score; NA = not available; NFL = neurofilament light; NINDC = control with noninflammatory disease control; RRMS = relapsing-remitting multiple sclerosis; $\mathrm{SC}=$ symptomatic control. 
terminated $>3$ months previously $(\mathrm{n}=14)$. A third group $(\mathrm{n}=20)$ had changed to another DMT with similar efficacy because of adverse effects or unsatisfactory adherence.

Participants with ONDs served as controls and were divided according to established definitions ${ }^{18}$ into those with inflammatory neurologic diseases (INDCs, $\mathrm{n}=15$ ), including CNS vasculitis $(\mathrm{n}=2)$, giant cell arteritis $(\mathrm{n}=1)$, antiphospholipid antibody syndrome $(\mathrm{n}=1)$, systemic lupus erythematosus $(\mathrm{n}=1)$, neuroborreliosis $(\mathrm{n}=1)$, sarcoidosis $(\mathrm{n}=3)$, chronic lymphatic leukemia with CNS involvement $(n=1)$, myelitis $(\mathrm{n}=1)$, neuromyelitis optica spectrum disorders $(\mathrm{n}=1)$, and unspecified demyelinating disease $(\mathrm{n}=3)$; those with noninflammatory neurologic diseases $(\mathrm{n}=16)$, including psychosis $(\mathrm{n}=$ 14), epilepsy ( $n=1)$, and Horner syndrome $(n=1)$; and symptomatic controls $(\mathrm{n}=14)$, including those with sensory symptoms $(n=6)$, headache $(n=2)$, dizziness $(n=1)$, fatigue $(n=$ $2)$, visual disturbance $(n=1)$, and unspecified neurologic symptoms $(\mathrm{n}=2)$.

Healthy blood donors and university students served as HCs $(n=42)$. None of the HCs had any neurologic signs or history of neurologic disease.

Clinical assessments and MRI. Patients were assessed once $(\mathrm{n}=138)$ or were followed up prospectively and assessed twice $(\mathrm{n}=148)$ by clinical neurologic examination performed by MSspecialized neurologists. Disability was scored by the Expanded Disability Status Scale (EDSS), ${ }^{20}$ and disease severity was scored by the Multiple Sclerosis Severity Score. ${ }^{21}$ A relapse was defined as an episode of neurologic disturbance lasting for at least 24 hours that could not be better explained by another cause..$^{22}$

A standard MRI protocol for MS with IV gadolinium (Gd) as contrast was used. Because Gd enhancement on MRI appears in the majority of cases during a period of up to 6 weeks (mean 3.07 weeks), ${ }^{17}$ we chose to include only MRIs performed 6 weeks before or after lumbar puncture and peripheral blood test

Figure 1 Serum NFL concentrations in patients with MS at baseline and followup and in $\mathrm{HCs}$

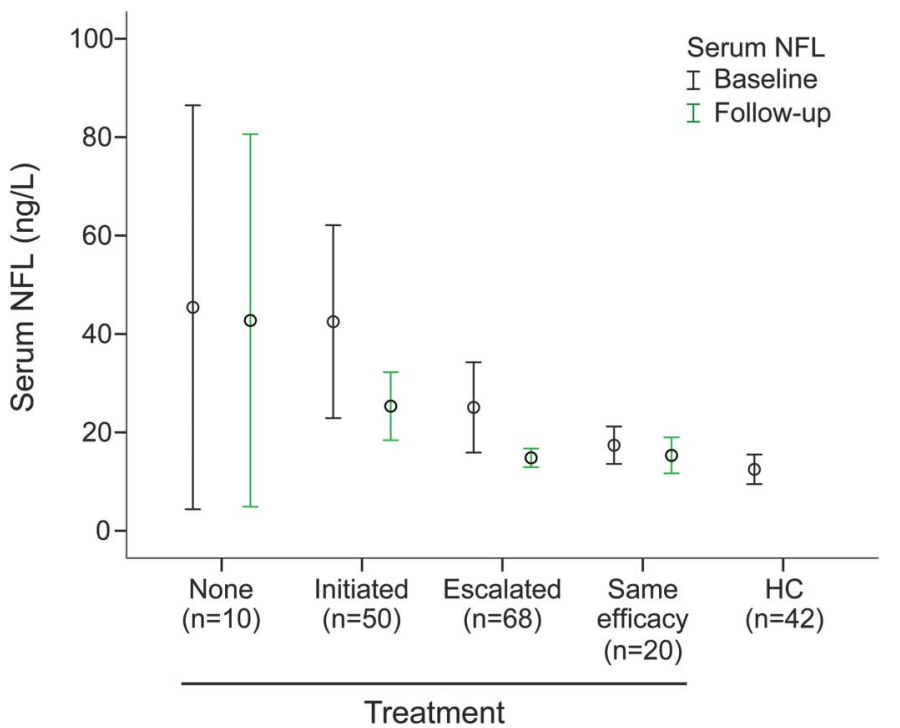

Serum NFL concentrations at baseline and follow-up in patients with MS who remained untreated, in patients with MS who initiated treatment with DMTs, in patients with MS who escalated DMT to more effective therapy, in patients with MS who changed treatment between DMTs of similar efficacy, and in HCs. The figure shows median and 95\% confidence interval of serum NFL concentrations. DMT = disease-modifying therapy; $\mathrm{HC}=$ healthy control; MS = multiple sclerosis; NFL = neurofilament light. $(\mathrm{n}=324)$ to investigate the influence of disease activity on MRI. The disease activity was defined as a relapse or Gdenhancing lesion. Because of the absence of data for T2 lesions on MRI, we used a modified no evidence of disease activity $(\mathrm{NEDA})^{23}$ : absence of contrast-enhancing lesions on MRI, absence of confirmed disability progression defined as the absence of increased posttreatment disability by 1.0 if the EDSS score was 0 to 5.5 at baseline or by 0.5 if the EDSS score was $\geq 6.0$ at baseline, and absence of relapses. ${ }^{24}$

Blood tests and CSF sampling. Samples of peripheral blood and CSF were obtained at the clinical assessments. The CSF samples were handled according to the consensus protocol of the BioMS-EU network for CSF biomarker research in MS. ${ }^{25}$ In patients with MS, the sampling period was dichotomized between relapse and remission. The relapse period was the time between relapse onset and 3 months later because increased concentrations of NFL are expected within this period of time. ${ }^{5,16}$

NFL analysis. All measurements were performed by boardcertified laboratory technicians in the Clinical Neurochemistry Laboratory at the Sahlgrenska University Hospital, i.e., by laboratory technicians who are licensed to perform clinical laboratory measurements by the National Board of Health and Welfare, a government agency in Sweden under the Ministry of Health and Social Affairs.

The concentration of NFL in CSF was measured with a sensitive sandwich ELISA method (NF-light ELISA kit; UmanDiagnostics $\mathrm{AB}$, Umeå, Sweden) according to the ELISA kit instructions. The lower limit of quantification (LLoQ) of the assay was $31 \mathrm{ng} / \mathrm{L}$. The intra-assay and interassay coefficients of variation were $<10 \%$.

The concentration of NFL in serum was determined with the NF-light assay, which was adapted for the Simoa platform with a Homebrew Kit (Quanterix Corp, Boston, MA). The LLoQ, which was determined by the blank mean signal at $610 \mathrm{SD}$, was $1.95 \mathrm{ng} / \mathrm{L}$. All samples were measured in duplicate and were well above the LLoQ. The intra-assay and interassay coefficients of variation were $<10 \%$. The method is described in detail elsewhere. ${ }^{26}$

Statistical analysis. Statistical calculations were performed with IBM SPSS Statistics 21 software (IBM Corp, Armonk, NY). Because of the nonnormal distribution of serum and CSF NFL levels, the analyses were performed with nonparametric tests, the Kruskal-Wallis test for comparison of multiple groups, and the Mann-Whitney test for comparison of 2 groups. The results are presented as median NFL levels and interquartile range. Correlations between serum and CSF NFL levels were analyzed with the Spearman rank correlation coefficient. The receiver operating characteristic (ROC) curve estimation was performed with the assumption of nonparametric distribution. The sensitivity and specificity were calculated by the Youden index, expressed as sensitivity + specificity -1 , to calculate optimal cutoffs that maximize both sensitivity and specificity.

Standard protocol approvals, registrations, and patient consents. All patients and controls participated voluntarily in the study and provided written informed consent. The regional ethics review boards in Uppsala and Stockholm, Sweden, approved the study.

RESULTS Comparison of serum and CSF NFL levels in patients with MS and controls. A total of 521 paired CSF and serum samples were analyzed. Serum and CSF NFL concentrations were significantly higher in patients with MS than in HCs $(p<0.001$ and 
$p<0.001$, respectively) and in controls with noninflammatory neurologic disease and symptomatic controls $(p<0.001$ and $p<0.001$, respectively). No difference was found between serum NFL concentrations in INDCs vs patients with MS, whereas CSF NFL concentrations were higher in INDCs than in patients with MS ( $p=0.019$, table). NFL concentrations in serum and CSF were higher in patients with RRMS with disease activity than in those without disease activity $(p<0.001$ and $p<0.001$, respectively). NFL concentrations in serum and CSF were also higher in patients with progressive MS with disease activity than in those without activity ( $p=0.009$ and $p<0.001$, respectively; table).

Effect of treatment on NFL levels in patients with MS. In untreated patients who initiated DMT, median NFL concentrations in serum decreased from 22.7 (17.5$39.1)$ to $20.2(13.7-28.9) \mathrm{ng} / \mathrm{L}(p=0.002)$, and CSF NFL concentrations decreased from 907 (564$1,608)$ to $460(350-675) \mathrm{ng} / \mathrm{L}(p<0.001)$. In $\mathrm{pa}-$ tients who escalated their DMT to more effective therapy, serum NFL concentrations decreased from $17.7(11.8-25.6)$ to $12.4(8.3-19.7) \mathrm{ng} / \mathrm{L}(p<$ $0.001)$, and CSF NFL concentrations decreased from $650(406-1,220)$ to $376(242-623) \mathrm{ng} / \mathrm{L}(p<$ $0.001)$. The patients who remained untreated at follow-up had unchanged serum and CSF NFL concentrations between the sampling time points:

Figure 2 Serum NFL concentrations in patients with MS with different numbers of Gd-enhancing lesions

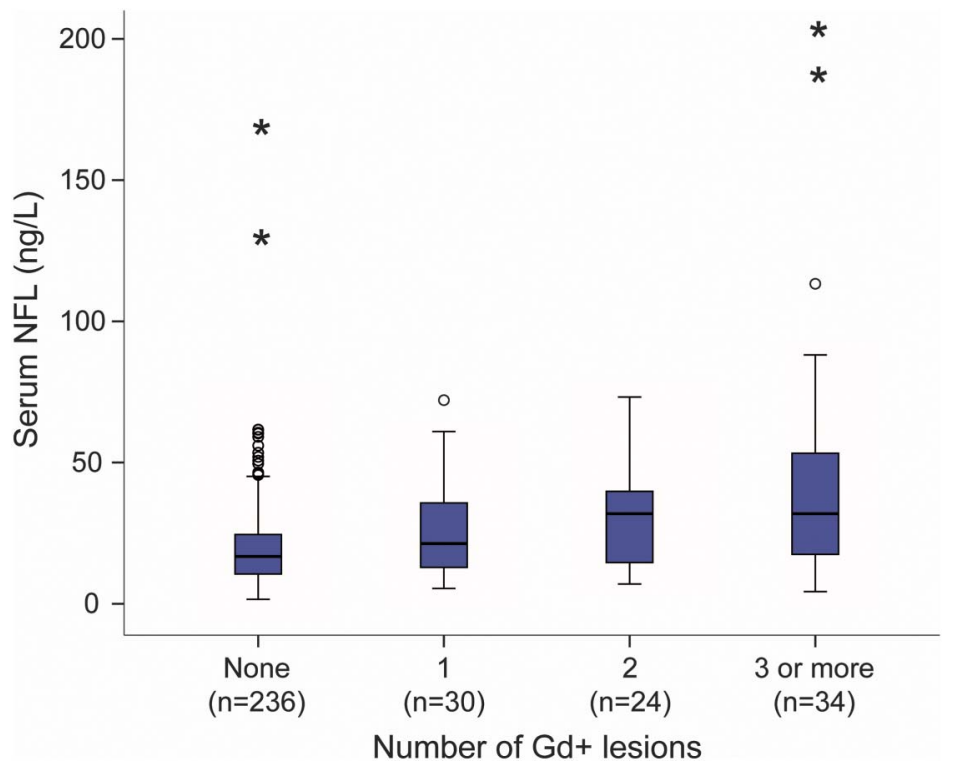

Serum NFL concentration in patients with no Gd-enhancing lesions $(\mathrm{n}=236)$ was 16.8 (IQR 10.5-24.6) $\mathrm{ng} / \mathrm{L}$, with 1 Gd-enhancing lesion $(\mathrm{n}=30$ ) was $21.3(\mathrm{IQR} 12.8-36.5) \mathrm{ng} / \mathrm{L}$, with 2 Gd-enhancing lesions ( $n=24$ ) was 31.9 (IQR 14.5-39.9) ng/L in serum, and with $\geq 3$ Gd-enhancing lesions ( $\mathrm{n}=34$ ) was 31.9 (IQR 17.4-55.6) $\mathrm{ng} / \mathrm{L}$. Box indicates IQR; bar indicates median, and whiskers indicate $95 \%$ confidence interval. Extreme values are marked with open dots $( \pm 1.5 \times$ $\mathrm{IQR}$ ) or with asterisks $( \pm 3 \times \mathrm{IQR})$. IQR $=$ interquartile range; $\mathrm{MS}=$ multiple sclerosis; $\mathrm{NFL}=$ neurofilament light.
$26.1(12.1-52)$ vs $26(11.6-53.8) \mathrm{ng} / \mathrm{L}(p=0.515)$ for serum and $1,003(631-1,529)$ vs 600 (451$1,177) \mathrm{ng} / \mathrm{L}(p=0.285)$ for CSF. Patients who changed treatment between DMTs with similar efficacy had stable serum and CSF NFL concentrations between the sampling time points: 15.7 (11-21.1) vs $15.4(9.1-18.3) \mathrm{ng} / \mathrm{L}(p=0.247)$ for serum and 565 $(375-863)$ vs $464(338-660) \mathrm{ng} / \mathrm{L}(p=0.086)$ for CSF (figure 1).

Relationship of NFL levels to disability, disease severity, and clinical and radiologic disease activity. Patients with a relapse $(n=86)$ within 3 months before sampling had higher NFL concentrations in serum of 19.1 (12.4-38.3) ng/L and in CSF of 925 (478$2,155) \mathrm{ng} / \mathrm{L}$ than patients in remission $(\mathrm{n}=346)$, who had NFL concentrations in serum of 17.2 (11.4-25.4) ng/L and in CSF of 570 (370-927) $\mathrm{ng} / \mathrm{L}(p=0.043$ and $p<0.001$, respectively). CSF NFL and serum NFL levels against the time from relapse onset are shown in figures e-1 and e-2 at Neurology.org. Serum and CSF NFL concentrations correlated weakly with EDSS $(\rho=0.380,95 \%$ confidence interval [CI] 0.297-0.457, $p<0.001$; and $\rho=$ $0.243,95 \%$ CI $0.153-0.329, p<0.001$, respectively) and with Multiple Sclerosis Severity Score $(\rho=0.392$, 95\% CI $0.310-0.468, p<0.001$; and $\rho=0.340$, 95\% CI 0.255-0.420, $p<0.001$, respectively).

Patients with Gd-enhancing lesions $(\mathrm{n}=88)$ had higher serum and CSF NFL concentrations (22.8 [14.7-41.3] and 1,187 [708-2,166] ng/L) than patients without $\mathrm{Gd}$-enhancing lesions $(\mathrm{n}=236,16.8$ [10.5-24.6] and 499 [330-795] ng/L, $p<0.001$ and $p<0.001$, respectively). Serum and CSF NFL concentrations increased with the number of Gdenhancing lesions (figure 2). Among the treated patients fulfilling the modified NEDA ( $\mathrm{n}=77$ ), $81.3 \%$ had normal levels of CSF NFL and $67.5 \%$ had normal levels of serum NFL.

Correlation between serum and CSF NFL concentrations, possible confounding factors, and sensitivity and specificity of serum NFL concentrations for disease activity. Correlations between serum and CSF NFL were $\rho=0.620$ (95\% CI $0.558-0.675, p<$ $0.001)$ for patients with MS, $\rho=0.385(95 \% \mathrm{CI}$ 0.092-0.616, $p<0.001$ ) for HCs, and $\rho=0.740$ (95\% CI $0.571-0.849, p<0.001)$ for patients with OND (figure 3, A-C). Disease duration, age, and sex did not significantly influence CSF or serum NFL concentrations. In 158 patients with MS, CSF/serum albumin ratio, which is a biomarker for blood-brain barrier integrity, did not correlate with NFL concentration.

The arbitrary cutoff value for increased NFL concentration in serum was defined as $18.2 \mathrm{ng} / \mathrm{L}$, which is 2 SDs above the mean NFL concentration in HCs. 
Figure 3 Correlation between serum and CSF NFL in patients with MS, HCs, and patients with ONDs

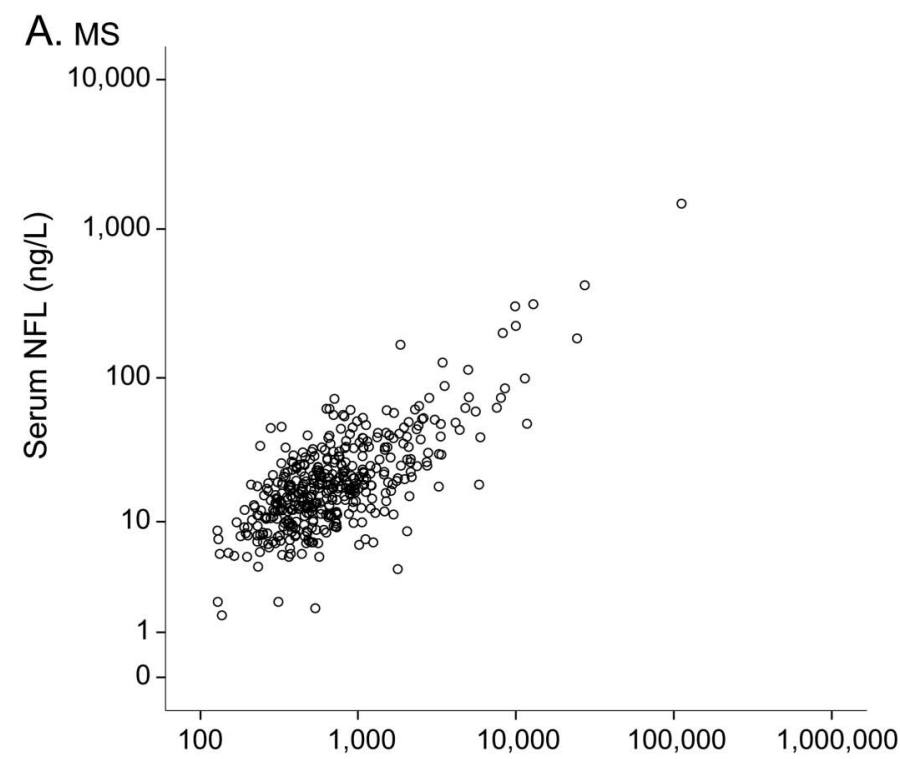

B. HC
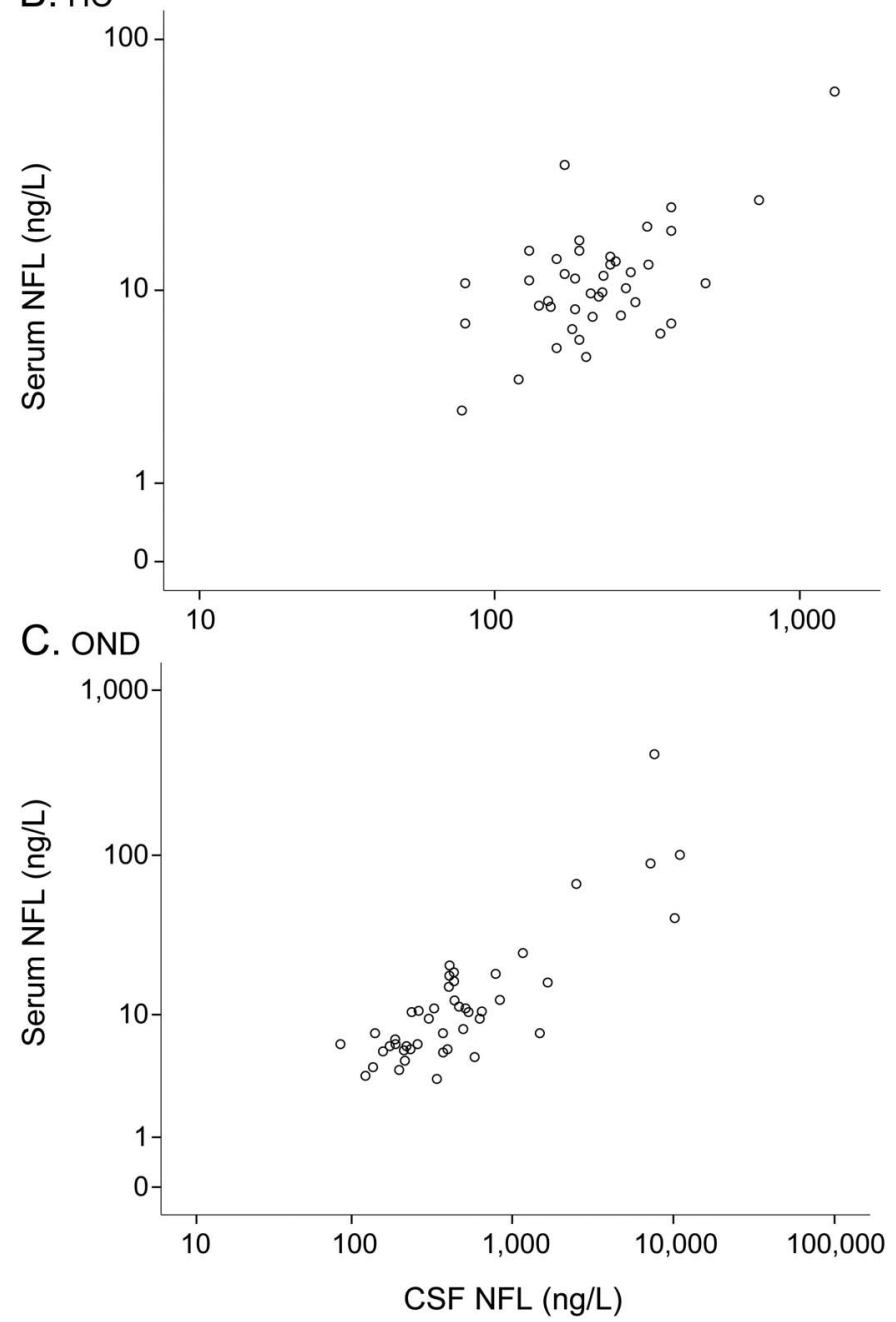

Correlation between NFL concentrations in serum and CSF (A) in patients with MS was $\rho=$ 0.620 (95\% Cl 0.558-0.675, $p<0.001)$, (B) in HCs was $\rho=0.385$ (95\% Cl 0.092-0.616, $p<0.001)$, and $(C)$ in patients with OND was $\rho=0.740(95 \% \mathrm{Cl} 0.571-0.849, p<0.001)$. $\mathrm{Cl}=$ confidence interval; $\mathrm{HC}=$ healthy control; $\mathrm{MS}=$ multiple sclerosis; $\mathrm{NFL}=$ neurofilament light; OND = other neurological disorder or symptom.
The age-dependent changes of CSF NFL were calculated by subtracting the expected level for the given age following the linear relationship reported in healthy individuals (i.e., $11.8 \mathrm{ng} / \mathrm{L} \times$ age -95 $\mathrm{ng} / \mathrm{L})^{27}$ from the measured NFL level.

The number of patients with RRMS with disease activity, along with the number of patients with RRMS with elevated NFL concentrations in serum and in CSF, was used to calculate sensitivity and specificity. Patients with progressive MS were excluded because increased NFL concentration in this group may be due to other degenerative processes and may not be confined to inflammatory activity. Patients with RRMS without disease activity had normal serum NFL concentrations in 93.4\% of the cases and normal CSF NFL concentrations in $80 \%$ of the cases. To evaluate the value of increased NFL concentration in serum and CSF as a screening test for disease activity in RRMS, a ROC curve was constructed (figure 4). The area under the curve (AUC) for serum NFL was 0.663 (95\% CI $0.591-0.735$, 80\% specificity and 45\% sensitivity), and the AUC for CSF NFL was 0.774 (95\% CI $0.714-0.835,75 \%$ specificity and 67\% sensitivity).

In patients with RRMS, $6.8 \%$ of serum samples and $32.4 \%$ of CSF samples were higher than the NFL cutoff level for those on higher-efficacy DMTs; the corresponding values in patients with RRMS on less efficacious DMTs were $12.6 \%$ and $37.8 \%$.

DISCUSSION The data in this study are based on a large set of paired serum and CSF samples from a real-life cohort of patients across a wide clinical and therapeutic spectrum. They support serum NFL as a biomarker for monitoring disease activity and treatment intervention in MS. We found that serum and CSF NFL concentrations were highly correlated and reacted similarly during the different stages of MS and in response to treatment with DMTs. High serum and CSF NFL concentrations were associated with relapse and with the number of contrastenhancing lesions on MRI. This was not confined to RRMS but was also found in patients with progressive disease course.

The effect of DMT on serum and CSF NFL concentrations was evaluated in all patients with MS regardless of whether the patients were treatment naive or on DMT at baseline. We confirmed that CSF NFL concentrations remained stable in patients who remained untreated or who switched treatment to DMT with similar efficacy, and NFL decreased in patients after initiating DMT or switching from first-line to second-line DMT. ${ }^{4,7}$ This response was also valid for serum NFL. Thus, the DMT efficacy was reflected by NFL concentrations, and serum NFL 
Figure 4 ROC curve showing specificity and sensitivity of NFL in serum and CSF for disease activity

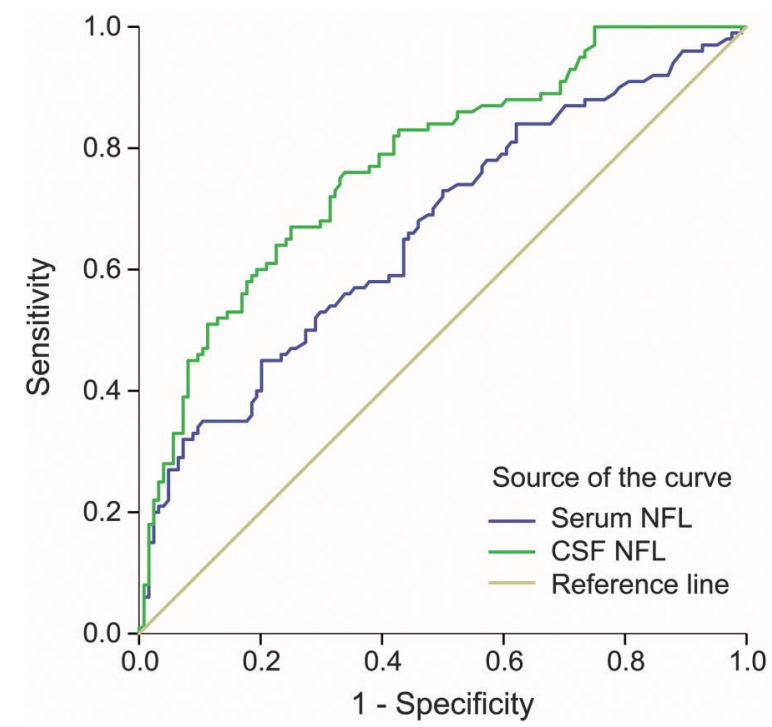

ROC curve with AUC for NFL in serum and CSF indicating specificity and sensitivity to discriminate patients with MS with disease activity from patients with MS without disease activity. AUC for serum NFL was 0.663 (95\% Cl 0.591-0.735, 80\% specificity and $45 \%$ sensitivity) and for CSF NFL was $0.774(95 \% \mathrm{Cl} 0.714-0.835,75 \%$ specificity and $67 \%$ sensitivity). $\mathrm{AUC}=$ area under the curve; $\mathrm{Cl}=$ confidence interval; $\mathrm{MS}=$ multiple sclerosis $\mathrm{NFL}=$ neurofilament light; $\mathrm{ROC}=$ receiver operating characteristic.

was as reliable as CSF NFL. Moreover, in patients with RRMS who were treated with effective DMT, we confirmed our previous finding in CSF that the NFL concentration in serum was not different from that in HCs. ${ }^{4,7}$

Because of its high specificity, normal concentration of serum NFL could be a useful measure for surveillance of subclinical activity in RRMS. Thus, a normal serum NFL concentration argues strongly against ongoing disease activity. In contrast, increased NFL concentrations occurred in patients who were clinically stable and who did not have contrastenhancing lesions on cerebral MRI. New T2 lesion formation may influence the NFL concentration, ${ }^{28,29}$ and the absence of T2 lesion data in our material probably affected the sensitivity of serum NFL to detect disease activity. However, spinal cord lesions, diffuse tissue injury of normal-appearing white matter, ${ }^{2}$ and gray matter pathology ${ }^{30}$ may also contribute to axonal injury. Thus, serum NFL may reveal asymptomatic ongoing axonal injury that is not seen on cerebral MRI.

NFL determination can detect axonal damage that occurred up to 3 months before sampling. ${ }^{5,6}$ Again, the high correlation between serum and CSF NFL suggests that the temporal course of serum NFL is similar to that described for CSF NFL. ${ }^{5,6,16}$ However, this has to be further investigated in prospective studies. In monitoring of the effect of DMT on axonal damage, a 3-month interval between blood tests for monitoring serum NFL would reveal the occurrence of new disease activity. ${ }^{4,5,16}$ However, we cannot determine from our data whether this would detect a stepwise accumulation of $\mathrm{T} 2$ lesions, accumulation of disability, or conversion to a progressive disease course. There is a need for long-term follow-up studies to collect data on the correlation between NFL concentrations over time and such outcomes.

The NFL concentration is related to the magnitude and rate of axonal damage and does not indicate the nature of the pathologic process. Compared with clinical measures and MRI, NFL determinations add new information that other methods may not be able to reveal. Even if fulfilling the modified NEDA, a proportion of patients still had elevated levels of NFL. Thus, NFL may contribute to NEDA for accessing disease-free status, and NFL and other body fluid biomarkers as complements to current clinical and MRI measures might improve the assessment of disease activity in MS. ${ }^{31}$

Although there is robust evidence supporting the CSF NFL concentration as a clinically useful biomarker, the need for lumbar puncture constitutes a major barrier for more widespread use, especially when repeat lumbar punctures are needed. Here, we show that serum and CSF NFL levels were highly correlated in MS and that this relationship also was present in HCs, i.e., throughout the entire detection range of the assays. The different degree of correlation in previous studies ${ }^{11,12,16}$ compared to this study probably depends on the use of various clinical materials and statistical methods, i.e., parametric tests or log-transformed data. We also confirmed the high correlation between serum and CSF NFL levels in patients with OND as in previous studies on traumatic injury ${ }^{15}$ and HIV encephalitis. ${ }^{12}$

Because of the multiple treatment options, it is increasingly important to accurately identify patients with MS with insufficient treatment response. Our data suggest that measuring serum NFL may be useful in trials and in clinical practice for evaluating the effect of DMTs in MS. Thus, in combination with clinical and MRI monitoring, serum NFL can add valuable new information that will facilitate the monitoring of disease activity and treatment decisions in MS.

\section{AUTHOR CONTRIBUTIONS}

L.N.: analysis and interpretation of data, acquisition of data, manuscript drafting. M.A., C.M.: study concept and design, acquisition of data, analysis and interpretation of data, critical revision of manuscript for intellectual content. P.S., M.K., M.G.: study concept and design, acquisition of data, critical revision of manuscript for intellectual content. A.S., F.P., T.O.: study concept and design, critical revision of manuscript for intellectual content. J.L.: study concept and design, critical revision of manuscript for intellectual content, manuscript drafting, study supervision. 
K.B., H.Z.: study concept and design, acquisition of data, critical revision of the manuscript for important intellectual content, obtaining funding.

\section{STUDY FUNDING}

This study was funded by grants from the Swedish Federal Governmen (LUA/ALF agreement), the Swedish Society of the Neurologically Disabled, the Research Foundation of the Multiple Sclerosis Society of Gothenburg, the Edit Jacobson Foundation, the Royal Society of Arts and Sciences in Gothenburg, the AFA foundation, the Swedish medical research council, the Swedish Brain Foundation, and the Torsten Söderberg Foundation at the Swedish Royal Academy of Sciences, as well as Novartis and Biogen (unconditional grants). Dr. Zetterberg is a Wallenberg Academy Fellow. Dr. Blennow holds the Torsten Söderberg Professorship in Medicine.

\section{DISCLOSURE}

L. Novakova reports no disclosures relevant to the manuscript. H. Zetterberg is a cofounder of Brain Biomarker Solutions in Gothenburg $\mathrm{AB}$, a GU Venture-based platform company at the University of Gothenburg, and has served at advisory boards for Roche Diagnostics, Eli Lilly, and Pharmasum Therapeutics. P. Sundström has received honoraria from Biogen Idec for serving as a member of a stipend committee. M. Axelsson has received compensation for lectures and/or advisory boards from Biogen, Genzyme, and Novartis. M. Khademi and M. Gunnarsson report no disclosures relevant to the manuscript. C. Malmeström has received honoraria for lectures and advisory boards from Biogen and Novartis. A. Svenningsson has served on advisory board for Sanofi-Genzyme and has received travel funding from Biogen Idec. T. Olsson has received unrestricted MS research grants from Biogen, Genzyme, Novartis, and AstraZeneca; compensation for lectures and/or advisory boards from Biogen, Genzyme, and Novartis; and research support from the Swedish research council, the Swedish Brain foundation, the AFA foundation, and the Knut and Alice Wallenberg foundation. F. Piehl has received unrestricted academic research grants from Biogen, Genzyme, and Novartis, as well as travel support and/or compensation for lectures and/or participation in advisory boards from Biogen, Genzyme, Merckserono, Novartis, Roche, and Teva, used exclusively for the support of research activities. K. Blennow has served as a consultant or on advisory boards for Alzheon, Eli-Lilly, Fujirebio Europe, IBL International, and Roche Diagnostics and is a cofounder of Brain Biomarker Solutions in Gothenburg AB, a GU Venture-based platform company at the University of Gothenburg. J. Lycke has received travel support and/or lecture honoraria from Biogen, Novartis, Teva, and Genzyme/Sanofi Aventis; has served on scientific advisory boards for Almirall, Teva, Biogen, Novartis, and Genzyme/Sanofi Aventis; serves on the editorial board of the Acta Neurologica Scandinavica; and has received unconditional research grants from Biogen, Novartis, and Teva. Go to Neurology.org for full disclosures.

Received January 8, 2017. Accepted in final form September 7, 2017.

\section{REFERENCES}

1. Norgren N, Rosengren L, Stigbrand T. Elevated neurofilament levels in neurological diseases. Brain Res 2003; 987:25-31.

2. Trapp BD, Peterson J, Ransohoff RM, Rudick R, Mork S, Bo L. Axonal transection in the lesions of multiple sclerosis. N Engl J Med 1998;338:278-285.

3. Axelsson M, Malmestrom C, Gunnarsson M, et al. Immunosuppressive therapy reduces axonal damage in progressive multiple sclerosis. Mult Scler 2014;20:43-50.

4. Gunnarsson M, Malmestrom C, Axelsson M, et al. Axonal damage in relapsing multiple sclerosis is markedly reduced by natalizumab. Ann Neurol 2011;69:83-89.

5. Lycke JN, Karlsson JE, Andersen O, Rosengren LE. Neurofilament protein in cerebrospinal fluid: a potential marker of activity in multiple sclerosis. J Neurol Neurosurg Psychiatry 1998;64:402-404.
6. Malmestrom C, Haghighi S, Rosengren L, Andersen O, Lycke J. Neurofilament light protein and glial fibrillary acidic protein as biological markers in MS. Neurology 2003;61:1720-1725.

7. Novakova L, Axelsson M, Khademi M, et al. Cerebrospinal fluid biomarkers of inflammation and degeneration as measures of fingolimod efficacy in multiple sclerosis. Mult Scler 2017;23:62-71.

8. Salzer J, Svenningsson A, Sundstrom P. Neurofilament light as a prognostic marker in multiple sclerosis. Mult Scler 2010;16:287-292.

9. Martinez MA, Olsson B, Bau L, et al. Glial and neuronal markers in cerebrospinal fluid predict progression in multiple sclerosis. Mult Scler 2015;21:550-561.

10. Rissin DM, Kan CW, Campbell TG, et al. Single-molecule enzyme-linked immunosorbent assay detects serum proteins at subfemtomolar concentrations. Nat Biotechnol 2010;28:595-599.

11. Kuhle J, Barro C, Andreasson U, et al. Comparison of three analytical platforms for quantification of the neurofilament light chain in blood samples: ELISA, electrochemiluminescence immunoassay and Simoa. Clin Chem Lab Med 2016;54:1655-1661.

12. Gisslen M, Price RW, Andreasson U, et al. Plasma concentration of the neurofilament light protein (NFL) is a biomarker of CNS injury in HIV infection: a crosssectional study. EBioMedicine 2016;3:135-140.

13. Shahim P, Gren M, Liman V, et al. Serum neurofilament light protein predicts clinical outcome in traumatic brain injury. Sci Rep 2016;6:36791.

14. Shahim PZH, Tegner Y, Blennow K. Serum neurofilament light as a biomarker for mild traumatic brain injury in contact sports. Neurology 2017;88:1788-1794.

15. Shahim P, Tegner Y, Gustafsson B, et al. Neurochemical aftermath of repetitive mild traumatic brain injury. JAMA Neurol 2016;73:1308-1315.

16. Bergman J, Dring A, Zetterberg $\mathrm{H}$, et al. Neurofilament light in CSF and serum is a sensitive marker for axonal white matter injury in MS. Neurol Neuroimmunol Neuroinflamm 2016;3:e271.

17. Cotton F, Weiner HL, Jolesz FA, Guttmann CR. MRI contrast uptake in new lesions in relapsing-remitting MS followed at weekly intervals. Neurology 2003;60: 640-646.

18. Teunissen C, Menge T, Altintas A, et al. Consensus definitions and application guidelines for control groups in cerebrospinal fluid biomarker studies in multiple sclerosis. Mult Scler 2013;19:1802-1809.

19. Sandberg L, Bistrom M, Salzer J, Vagberg M, Svenningsson A, Sundstrom P. Vitamin D and axonal injury in multiple sclerosis. Mult Scler 2016;22: 1027-1031.

20. Kurtzke JF. Rating neurologic impairment in multiple sclerosis: an Expanded Disability Status Scale (EDSS). Neurology 1983;33:1444-1452.

21. Roxburgh RH, Seaman SR, Masterman T, et al. Multiple Sclerosis Severity Score: using disability and disease duration to rate disease severity. Neurology 2005;64:11441151.

22. McDonald WI, Compston A, Edan G, et al. Recommended diagnostic criteria for multiple sclerosis: guidelines from the International Panel on the Diagnosis of Multiple Sclerosis. Ann Neurol 2001;50:121-127.

23. Giovannoni G, Tomic D, Bright JR, Havrdova E. "No evident disease activity": the use of combined assessments 
in the management of patients with multiple sclerosis Mult Scler 2017;23:1179-1187.

24. Wiendl H, Meuth SG. Pharmacological approaches to delaying disability progression in patients with multiple sclerosis. Drugs 2015;75:947-977.

25. Teunissen CE, Petzold A, Bennett JL, et al. A consensus protocol for the standardization of cerebrospinal fluid collection and biobanking. Neurology 2009;73:1914-1922.

26. Rohrer JD, Woollacott IO, Dick KM, et al. Serum neurofilament light chain protein is a measure of disease intensity in frontotemporal dementia. Neurology 2016;87: 1329-1336.

27. Vagberg $\mathrm{M}$, Norgren $\mathrm{N}$, Dring $\mathrm{A}$, et al. Levels and age dependency of neurofilament light and glial fibrillary acidic protein in healthy individuals and their relation to the brain parenchymal fraction. PLoS One 2015;10:e0135886.
28. Burman J, Zetterberg H, Fransson M, Loskog AS, Raininko R, Fagius J. Assessing tissue damage in multiple sclerosis: a biomarker approach. Acta Neurol Scand 2014; 130:81-89.

29. Novakova L, Axelsson M, Khademi M, et al. Cerebrospinal fluid biomarkers as a measure of disease activity and treatment efficacy in relapsing-remitting multiple sclerosis. J Neurochem 2017;141:296-304.

30. Calabrese M, Magliozzi R, Ciccarelli O, Geurts JJ, Reynolds R, Martin R. Exploring the origins of grey matter damage in multiple sclerosis. Nat Rev Neurosci 2015;16:147-158.

31. Bonnan M, Marasescu R, Demasles S, Krim E, Barroso B. No evidence of disease activity (NEDA) in MS should include CSF biology: towards a "disease-free status score.” Mult Scler Relat Disord 2017;11:51-55.

\section{This Week's Neurology ${ }^{\circledR}$ Podcast}

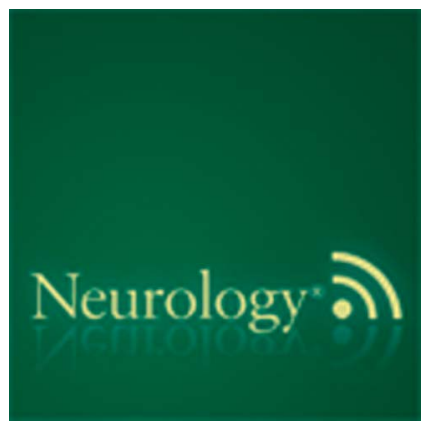

Midlife systemic inflammatory markers are associated with late-life brain volume: The ARIC study (see p. 2262)

This podcast begins and closes with Dr. Robert Gross, Editor-inChief, briefly discussing highlighted articles from the November 28, 2017, issue of Neurology. In the first segment, Dr. Jeff Burns talks with Dr. Keenan Walker about his paper on the association between systemic inflammation and brain volume over time. For our "What's Trending" segment, Dr. Stacey Clardy focuses her interview with Dr. Annette Langer-Gould on her recent Neurology article on breast feeding, ovulatory years, and risk of multiple sclerosis.

Disclosures can be found at Neurology.org.

At Neurology.org, click on "RSS" in the Neurology Podcast box to listen to the most recent podcast and subscribe to the RSS feed.

CME Opportunity: Listen to this week's Neurology Podcast and earn 0.5 AMA PRA Category 1 CME Credits ${ }^{\mathrm{TM}}$ by answering the multiple-choice questions in the online Podcast quiz.

\section{Save These Dates for AAN CME Opportunities!}

Mark these dates on your calendar for exciting continuing education conferences by the American Academy of Neurology. Learn more at $A A N$.com/conferences.

\section{Breakthroughs in Neurology Conference}

- January 12-15, 2018, Orlando, FL, at the Caribe Royale Orlando 


\section{Neurology}

\section{Monitoring disease activity in multiple sclerosis using serum neurofilament light protein}

Lenka Novakova, Henrik Zetterberg, Peter Sundström, et al.

Neurology 2017;89;2230-2237 Published Online before print October 27, 2017

DOI 10.1212/WNL.0000000000004683

This information is current as of October 27, 2017

\section{Updated Information \& Services}

Supplementary Material

\section{References}

Citations

Subspecialty Collections

Permissions \& Licensing

Reprints including high resolution figures, can be found at: http://n.neurology.org/content/89/22/2230.full

Supplementary material can be found at: http://n.neurology.org/content/suppl/2017/10/27/WNL.0000000000004 683.DC1

This article cites 31 articles, 8 of which you can access for free at: http://n.neurology.org/content/89/22/2230.full\#ref-list-1

This article has been cited by 12 HighWire-hosted articles: http://n.neurology.org/content/89/22/2230.full\#\#otherarticles

This article, along with others on similar topics, appears in the following collection(s):

Cerebrospinal Fluid

http://n.neurology.org/cgi/collection/cerebrospinal_fluid

Multiple sclerosis

http://n.neurology.org/cgi/collection/multiple_sclerosis

Information about reproducing this article in parts (figures,tables) or in its entirety can be found online at:

http://www.neurology.org/about/about_the_journal\#permissions

Information about ordering reprints can be found online:

http://n.neurology.org/subscribers/advertise

Neurology ${ }^{\circledR}$ is the official journal of the American Academy of Neurology. Published continuously since 1951, it is now a weekly with 48 issues per year. Copyright Copyright ( 2017 The Author(s). Published by Wolters Kluwer Health, Inc. on behalf of the American Academy of Neurology.. All rights reserved. Print ISSN: 0028-3878. Online ISSN: 1526-632X.

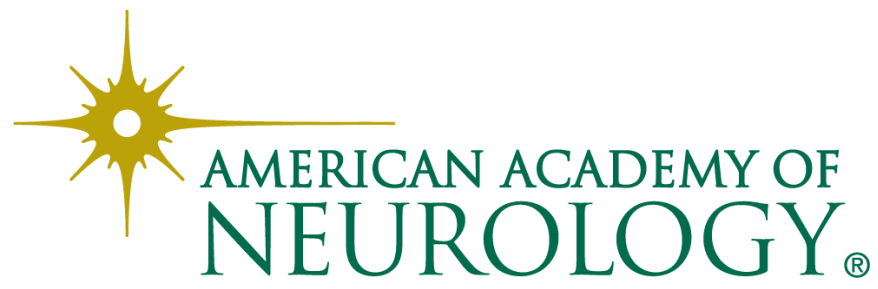

